\title{
An ab Initio Investigation of Halocarbenes
}

\author{
Martin Schwartz* and Paul Marshall* \\ Department of Chemistry, University of North Texas, PO Box 305070, Denton, Texas 76203-5070
}

Received: June 11, 1999; In Final Form: July 22, 1999

\begin{abstract}
Gaussian-2 and QCI theory with basis sets up to 6-311+G(3df,2p) have been employed to obtain information about the carbenes (methylenes) $\mathrm{CH}_{2}, \mathrm{CHBr}, \mathrm{CHCl}, \mathrm{CHF}, \mathrm{CHI}, \mathrm{CBr}_{2}, \mathrm{CBrCl}, \mathrm{CBrF}, \mathrm{CBrI}, \mathrm{CCl}_{2}, \mathrm{CClF}, \mathrm{CClI}$, $\mathrm{CF}_{2}$, and $\mathrm{CI}_{2}$. Geometries and vibrational frequencies for the singlet and triplet states, and the singlet - triplet splittings, have been characterized and are discussed in the context of the electronegativities of the substituents. Isodesmic reactions were used to derive a consistent set of enthalpies of formation for the 14 halocarbenes. Where there are measurements, the computed results compare well, and substantial gaps in the current literature are filled.
\end{abstract}

\section{Introduction}

Methylene (carbene, $\mathrm{CH}_{2}$ ) and substituted carbenes have long played a central role in organic chemistry ${ }^{1}$ and have been the focus of numerous theoretical investigations. ${ }^{2,3}$ The reactivity of methylene is critically dependent on the electronic state. ${ }^{4}$ Both the triplet ground state and the low-lying excited singlet state are energetically accessible and are explicitly taken into account in current hydrocarbon combustion models. ${ }^{5}$ Similar remarks apply to halogenated carbenes, which are important intermediates in the incineration of fluorine- and chlorine-containing wastes and in the combustion inhibition mechanisms of fluorine-, bromine-, and iodine-containing flame suppressants. ${ }^{6}$

However, in the case of halocarbenes there are few experimental data for use in combustion modeling. As discussed below, there is little accurate information on the geometry, vibrational frequencies, singlet-triplet energy gaps, and thermochemistry for the halocarbenes. For example, the recommended $\Delta_{\mathrm{f}} H^{\circ}$ for fluorine- and chlorine-containing halocarbenes in three standard thermochemical compilations ${ }^{7-9}$ range over $60 \mathrm{~kJ} \mathrm{~mol}^{-1}$. In addition, there is little information for bromineand iodine-containing species. Here we have extended the ab initio methodology we applied previously to the methylidyne series. ${ }^{10}$ The major goal of the present work is to resolve some of these discrepancies via ab initio methods and to provide a consistent set of data for the 14 halocarbenes CXY, where X, $\mathrm{Y}=\mathrm{H}, \mathrm{F}, \mathrm{Cl}, \mathrm{Br}$, I. This complete series has been examined before, notably by Irikura et al. who focused on the singlettriplet gap, and scaled results obtained with modest levels of theory to match calibration molecules. ${ }^{11}$ In this work, we employ QCI theory with basis sets up to $6-311+\mathrm{G}(3 \mathrm{df}, 2 \mathrm{p})$ to obtain information for the halocarbenes. Where there are measurements, the computed results compare well, substantial gaps in the database are filled, and in particular, information is now provided for bromine- and iodine-containing carbenes.

\section{Computational Methods}

Calculations were performed on the singlet and triplet states of the 14 halo- and dihalocarbenes, using the GAUSSIAN-94 quantum mechanical code. ${ }^{12}$ Additional computations were performed on $\mathrm{CH}_{2}\left({ }^{1} \mathrm{~A}_{1}\right), \mathrm{CH}_{2}\left({ }^{3} \mathrm{~B}_{1}\right), \mathrm{CH}_{4}$, and a series of

*Corresponding author. E-mail: marty@unt.edu; marshall@unt.edu reference halomethanes. ${ }^{13}$ Energies were obtained at two levels. First, the Gaussian-2 (G2) protocol ${ }^{14}$ was utilized to obtain $E_{0^{-}}$ [G2], which approximates QCISD(T)/6-311+G(3df,2p)//MP2(full)/6-31G(d) energies (including scaled HF/6-31G(d) zeropoint energies, ZPE). Second, to assess the effect of improving the level of geometry calculation and removing the additivity approximations of the $\mathrm{G} 2$ procedure, nonapproximate QCISD(T)/6-311+G(3df,2p) energies, $E_{0}[\mathrm{QCISD}(\mathrm{T})]$, were computed using geometries and frequencies obtained at the QCISD/6$311 \mathrm{G}(\mathrm{d}, \mathrm{p})$ level; frequencies were scaled by 0.954 for the ZPE calculations (vide infra).

Computations on species containing bromine or iodine employed the recently developed basis sets of McGrath, Radom, and co-workers. ${ }^{15,16} \mathrm{G} 2$ energies were determined using the nonrelativistic all-electron (AE) versions of these bases, whereas nonapproximate QCISD(T) energies employed the bases incorporating Hay-Wadt relativistic effective core potentials (ECPs). ${ }^{16}$

Values of $E_{0}[\mathrm{G} 2]$ and $E_{0}[\mathrm{QCISD}(\mathrm{T})]$ for the singlet and triplet states of the halocarbenes as well as for the reference compounds are available as Supporting Information. Scaled frequencies of the reference compounds are also contained in the Supporting Information.

\section{Results and Discussion}

A. Geometries and Vibrational Frequencies. Bond lengths and angles of the singlet and triplet states of $\mathrm{CH}_{2}$ and the halocarbenes, computed at the QCISD/6-311G(d,p) level of theory, are displayed in Table 1; also contained in the table are the available experimental geometries. ${ }^{7,17-19}$ Agreement with the few accurately measured geometries of several fluoro- and chlorocarbenes is quite good: bond lengths match to within 0.01 $\AA\left(1 \AA=10^{-10} \mathrm{~m}\right)$ and angles to within $1^{\circ}$. Not surprisingly, there are larger discrepancies with some of the reported approximate geometric parameters for several halocarbenes (obtained by analogy with other halocarbons). In general (with the exception of $\mathrm{CI}_{2}$ ), the approximate bond lengths are lower than those computed here, by $0.03-0.05 \AA$.

Geometries of singlet and triplet monohalocarbenes and $\mathrm{CF}_{2}$, computed at the BLYP and BVWN5 levels using double or triple- $\zeta$ bases, have been reported recently. ${ }^{20}$ The DFT bond lengths were somewhat longer than those obtained here and the experimental values. On the other hand, a very recent calcula- 
TABLE 1: Calculated and Experimental Geometries in Halocarbenes ${ }^{a, b}$

\begin{tabular}{|c|c|c|c|c|c|c|}
\hline \multirow[b]{2}{*}{ carbene } & \multicolumn{2}{|r|}{$R_{1}$} & \multicolumn{2}{|r|}{$R_{2}$} & \multicolumn{2}{|r|}{$\theta$} \\
\hline & calcd & $\operatorname{expt}^{c}$ & calcd & $\operatorname{expt}^{c}$ & calcd & $\operatorname{expt}^{c}$ \\
\hline \multicolumn{7}{|c|}{ A. Singlets } \\
\hline $\mathrm{CH}_{2}$ & 1.116 & $1.107 \pm 0.002^{d}$ & 1.116 & $1.107 \pm 0.002^{d}$ & 101.0 & $102.4 \pm 0.4^{d}$ \\
\hline $\mathrm{CHBr}$ & 1.881 & $1.854^{e}$ & 1.114 & $1.116^{e}$ & 100.7 & $102.6^{e}$ \\
\hline $\mathrm{CHCl}$ & 1.711 & $1.689 \pm 0.005$ & 1.114 & $1.120 \pm 0.005$ & 102.0 & $103 \pm 1$ \\
\hline $\mathrm{CHF}$ & 1.312 & $1.314 \pm 0.005$ & 1.126 & $1.120 \pm 0.005$ & 102.1 & $101.8 \pm 1$ \\
\hline $\mathrm{CHI}$ & 2.082 & & 1.115 & & 100.2 & \\
\hline $\mathrm{CBr}_{2}$ & 1.911 & $(1.87 \pm 0.05)$ & 1.911 & $(1.87 \pm 0.05)$ & 110.7 & $(110 \pm 10)$ \\
\hline $\mathrm{CBrCl}$ & 1.918 & & 1.725 & & 110.4 & \\
\hline $\mathrm{CBrF}$ & 1.952 & & 1.293 & & 106.9 & \\
\hline $\mathrm{CBrI}$ & 2.131 & & 1.906 & & 111.7 & \\
\hline $\mathrm{CCl}_{2}$ & 1.730 & $(1.70 \pm 0.05)$ & 1.730 & $(1.70 \pm 0.05)$ & 110.0 & $(108 \pm 5)$ \\
\hline $\mathrm{CClF}$ & 1.753 & $(1.70 \pm 0.05)$ & 1.298 & $(1.30 \pm 0.05)$ & 106.5 & $(105 \pm 10)$ \\
\hline $\mathrm{CClI}$ & 2.141 & & 1.720 & & 111.4 & \\
\hline $\mathrm{CF}_{2}$ & 1.302 & $1.3035 \pm 0.0001$ & 1.302 & $1.3035 \pm 0.0001$ & 104.7 & $104.78 \pm 0.02$ \\
\hline CFI & 2.189 & & 1.290 & & 107.4 & \\
\hline $\mathrm{CI}_{2}$ & 2.123 & $(2.12 \pm 0.05)$ & 2.123 & $(2.12 \pm 0.05)$ & 112.6 & $(110 \pm 10)$ \\
\hline \multicolumn{7}{|c|}{ B. Triplets } \\
\hline $\mathrm{CH}_{2}$ & 1.083 & $1.0766 \pm 0.0014^{f}$ & 1.083 & $1.0766 \pm 0.0014^{f}$ & 132.6 & $134.037 \pm 0.045^{f}$ \\
\hline $\mathrm{CHBr}$ & 1.834 & & 1.086 & & 126.6 & \\
\hline $\mathrm{CHCl}$ & 1.678 & & 1.085 & & 125.7 & \\
\hline $\mathrm{CHF}$ & 1.318 & & 1.089 & & 121.3 & \\
\hline $\mathrm{CHI}$ & 2.016 & & 1.087 & & 128.4 & \\
\hline $\mathrm{CBr}_{2}$ & 1.852 & & 1.852 & & 129.8 & \\
\hline $\mathrm{CBrCl}$ & 1.853 & & 1.688 & & 128.6 & \\
\hline $\mathrm{CBrF}$ & 1.868 & & 1.315 & & 123.9 & \\
\hline $\mathrm{CBrI}$ & 2.041 & & 1.850 & & 131.3 & \\
\hline $\mathrm{CCl}_{2}$ & 1.689 & & 1.689 & & 127.5 & \\
\hline $\mathrm{CClF}$ & 1.697 & & 1.317 & & 122.8 & \\
\hline $\mathrm{CCII}$ & 2.044 & & 1.688 & & 130.1 & \\
\hline $\mathrm{CF}_{2}$ & 1.318 & & 1.318 & & 119.5 & \\
\hline CFI & 2.069 & & 1.315 & & 124.9 & \\
\hline $\mathrm{CI}_{2}$ & 2.038 & & 2.038 & & 132.9 & \\
\hline
\end{tabular}

${ }^{a}$ Distances are in angstroms, and angles are in degrees. ${ }^{b}$ Computed at the QCISD/6-311G(d,p) level. ${ }^{c}$ Except where noted, experimental geometries are from ref 7. Empirical estimates are in parentheses. ${ }^{d}$ Reference 17. ${ }^{e}$ Reference 18. ${ }^{f}$ Reference 19.

tion ${ }^{21}$ on $\mathrm{CF}_{2}\left({ }^{1} \mathrm{~A}_{1}\right)$ at the B3LYP/6-311+G(2df) level yielded a bond length and angle virtually identical to those found here. A recent investigation ${ }^{22}$ of singlet and triplet $\mathrm{CHF}$ at the MRCI and $\operatorname{CCSD}(\mathrm{T})$ levels of theory report bond lengths and angles which agree to within $0.005 \AA$ and $0.3^{\circ}$, respectively, of QCISD(T) values computed here.

From Table 1, one observes the well-known increase in XCY bond angle (by $20^{\circ}-30^{\circ}$ ) in the triplet, which has been explained both on the basis of decreased valence shell electron repulsion and diminished s-character of the singly occupied nonbonding orbital (increasing the percent $\mathrm{s}$ in the bonding orbitals). ${ }^{3}$ It may be seen also that, with the exception of $\mathrm{C}-\mathrm{F}$ bonds (which increase by approximately $0.02 \AA$ ), triplet carbene bonds are shorter than those of the singlets (by $\sim 0.03 \AA$ for $\mathrm{C}-\mathrm{H}$ to $\sim 0.09$ $\AA$ for C-I bonds). This observation, too, is consistent with increased s character of bonding orbitals in the triplet species.

Analysis of the data reveals fairly regular trends in the geometric parameters with substituent electronegativity. To isolate the influence of a given substituent on the bond length, $R$, it is useful to plot the value of $R(\mathrm{C}-\mathrm{X})$ for fixed $\mathrm{X}$ in the series of carbenes, $\mathrm{CXY}$, as a function of the Pauling electronegativity ${ }^{23}$ of the second substituent $\left[\chi_{\mathrm{Y}}\right]$; for example, $R(\mathrm{C}-\mathrm{F})$ in the series $\mathrm{CHF}, \mathrm{CFI}, \mathrm{CFBr}, \mathrm{CFCl}, \mathrm{CF}_{2}$. The results for the singlet halocarbenes are displayed in parts $\mathrm{A}[\mathrm{C}-\mathrm{F}$ and $\mathrm{C}-\mathrm{Cl}]$ and $\mathrm{B}[\mathrm{C}-\mathrm{Br}$ and $\mathrm{C}-\mathrm{I}]$ of Figure 1 . From the figures, one observes a moderate to substantial increase in $\mathrm{C}-\mathrm{Cl}, \mathrm{C}-\mathrm{Br}$, and $\mathrm{C}-\mathrm{I}$ bond lengths with rising electronegativity of the second substituent. If one ignores the anomalously long $\mathrm{C}-\mathrm{F}$ bond in $\mathrm{CHF}$, there is a similar, although rather small, rise of the $\mathrm{C}-\mathrm{F}$ bond lengths with increasing $\chi_{\mathrm{Y}}$. Triplet bond lengths exhibit a similar, although smaller trend.
One finds a similarly regular trend in XCY bond angles with substituent electronegatively. This is illustrated in Figure 2, where we have plotted the angle versus $\chi_{\mathrm{Y}}$ for the singlet states of the four series, $\mathrm{CXY}, \mathrm{X}=\mathrm{F}, \mathrm{Cl}, \mathrm{Br}$, I. One sees that, with the exception of the monohalocarbenes [CXH, $\mathrm{X}=\mathrm{F}, \mathrm{Cl}, \mathrm{Br}$, I], the bond angle decreases monotonically with rising substituent electronegativity. The triplet bond angles exhibit similar, even larger, variations of bond angle with increasing $\chi_{\mathrm{Y}}$.

The observed trends in both bond angles and lengths are consistent with Bent's rule, ${ }^{24}$ which predicts that the $\mathrm{p}$ character of bonding orbitals increases with substituent electronegativity. The anomalously low CHX bond angles may result from the hydrogen atom's low steric requirements.

Contained in Table 2 are computed QCISD/6-311G(d,p) vibrational frequencies of the singlet and triplet halocarbenes, together with assignments and reported frequencies, where available. ${ }^{7}$ Experimental data are lacking for many of the carbenes, particularly in the triplet state, due at least in part to their highly reactive nature.

The QCISD frequencies were approximately 5\% higher on average than experimental values. This is not surprising and may be attributed almost entirely to anharmonicity in the measured values. It was found that the RMS deviation from experiment is minimized by using a scale factor, 0.954 , with a resultant RMS error of $28 \mathrm{~cm}^{-1}$. Computed frequencies in the table have been scaled by this factor.

It was satisfying to find that the scale factor derived independently by comparison of calculated and experimental frequencies of the reference halomethanes ${ }^{13}$ was virtually identical (0.955) to that for the halocarbenes. The RMS error for the halomethanes was lower $\left(<16 \mathrm{~cm}^{-1}\right)$, which likely results 

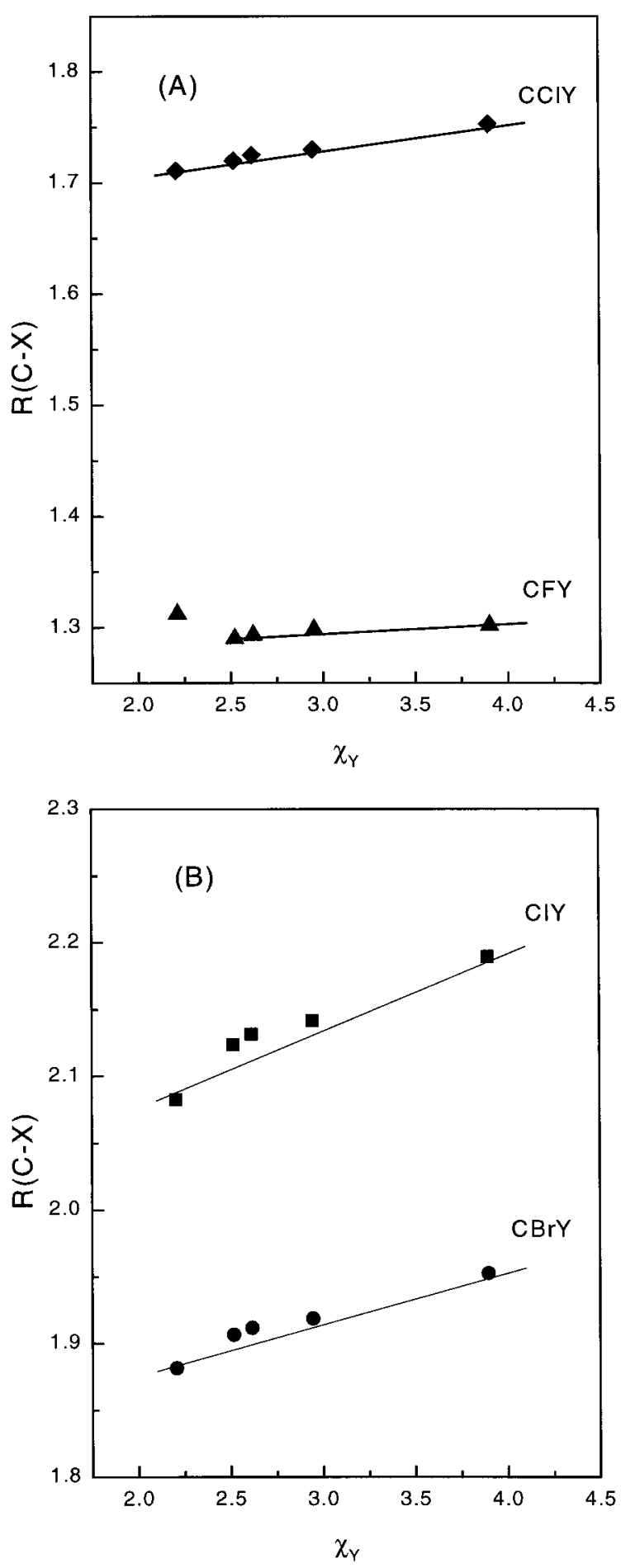

Figure 1. Singlet state $C-X$ bond lengths versus substituent electronegativity, $\chi_{\mathrm{Y}}$, for the series $\mathrm{CXY}(\mathrm{X}=\mathrm{F}, \mathrm{Cl}, \mathrm{Br}, \mathrm{I})$. (A) $\mathrm{CFY}$, triangles; CCIY, diamonds. (B) CBrY, circles; CIY, squares.

from the greater accuracy of experimental data for the stable halomethanes.

On the basis of the agreement of the scaled QCISD frequencies to experimental data on the halomethanes and the halocarbenes where frequencies have been measured, it is suggested that the values in Table 2 furnish reasonable estimates for the vibrational frequencies of the other members of this series where experimental data are unavailable.

B. Singlet-Triplet Energy Gaps. For methylene itself, the triplet species is the more stable, by approximately $40 \mathrm{~kJ}$ $\mathrm{mol}^{-1} \cdot{ }^{25,26}$ However, both experimental measurements ${ }^{26-28}$ and

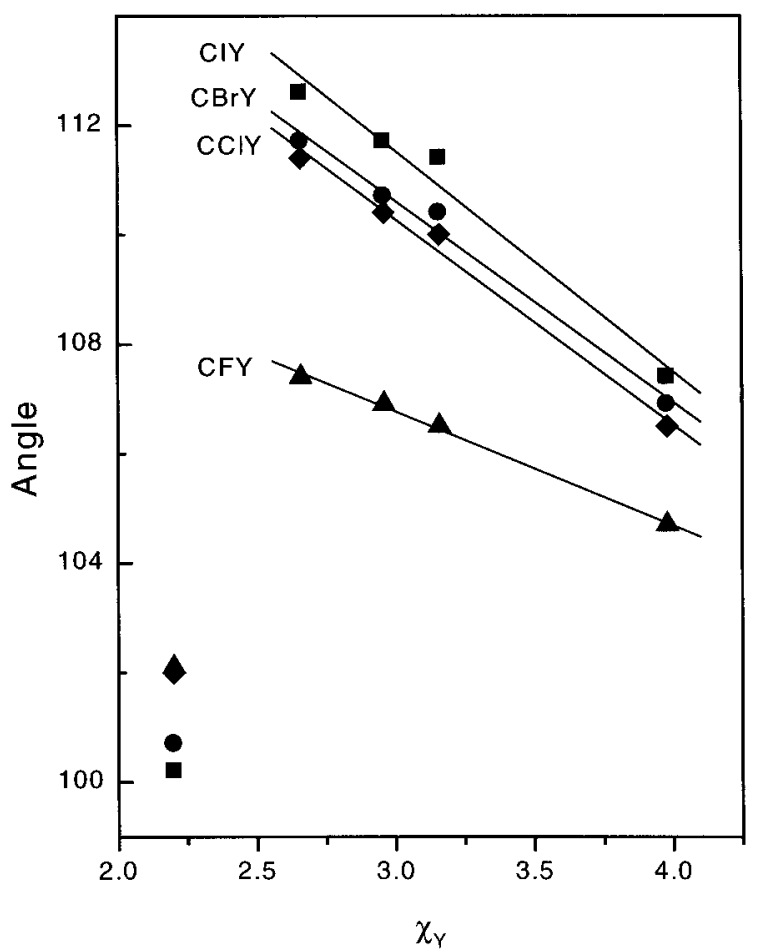

Figure 2. Singlet state $\mathrm{X}-\mathrm{C}-\mathrm{Y}$ angles versus substituent electronegativity, $\chi_{\mathrm{Y}}$, for the series $\mathrm{CXY}(\mathrm{X}=\mathrm{F}, \mathrm{Cl}, \mathrm{Br}, \mathrm{I})$. CFY, triangles; $\mathrm{CClY}$, diamonds; $\mathrm{CBrY}$, circles; $\mathrm{CIY}$, squares.

theoretical calculations ${ }^{20,22,29,30-35}$ have shown a marked singlet state stabilization upon halogen substitution.

We have computed adiabatic energy gaps, $\Delta E_{\mathrm{S}-\mathrm{T}}=E_{0}$ (trip) $-E_{0}$ (sing) (which include vibrational ZPE) for all of the haloand dihalocarbenes using both G2 and QCISD(T)/6-311+G(3df,2p) energies. The results are contained in Table 3, together with some reported experimental measurements and other calculations. With the exception of $\Delta E_{\mathrm{S}-\mathrm{T}}\left(\mathrm{CH}_{2}\right)$, the singlets are predicted in all cases to be the more stable of the two electronic states.

One observes immediately that there is a comparatively large difference in the two sets of computed results. The deviations are not random. Rather, the G2 energy gaps are greater than the QCISD(T) energy diffferences by an approximately constant amount, with $\Delta E_{\mathrm{S}-\mathrm{T}}[\mathrm{G} 2]-\Delta E_{\mathrm{S}-\mathrm{T}}[\mathrm{QCISD}(\mathrm{T})]=14.5 \pm 1.6$ $\mathrm{kJ} \mathrm{mol}^{-1}$. This deviation can be ascribed almost completely to the high-level corrections ${ }^{14}$ (HLCs) included in the G2 singlet and triplet energies, which contribute $+12.1 \mathrm{~kJ} \mathrm{~mol}^{-1}$ to $\Delta E_{\mathrm{S}-\mathrm{T}}[\mathrm{G} 2]$.

A comparison with the measured energy gaps in $\mathrm{CH}_{2}$ and several halocarbenes (Table 3 ) reveals that in every case where experimental data is available, $\Delta E_{\mathrm{S}-\mathrm{T}}[\mathrm{QCISD}(\mathrm{T})]$ lies closer to the measured value. Indeed, one finds an overall excellent agreement with experiment, with the computed value often lying within $3 \mathrm{~kJ} \mathrm{~mol}^{-1}$ of the measured gap. For those cases where the deviation is greater $(\mathrm{CHBr}, \mathrm{CHCl}$, and $\mathrm{CHI})$, there is a very large experimental uncertainty.

It is at first surprising to find that the HLCs, introduced empirically into the $\mathrm{G} 2$ method to improve agreement with experimental data, actually introduce a comparatively large error into calculated singlet-triplet energy gaps in the halocarbenes. However, it must be noted that there were no data on transition energies between bound electronic states of differing multiplicity in the G2 test set from which the HLCs were derived. In this context, it is relevant to note that the atomization energies of $\mathrm{CH}_{2}\left({ }^{1} \mathrm{~A}_{1}\right)$ and $\mathrm{CH}_{2}\left({ }^{3} \mathrm{~B}_{1}\right)$ computed by the $\mathrm{G} 2$ method agree with 
TABLE 2: Calculated and Experimental Vibrational Frequencies in Halocarbenes ${ }^{a}$

\begin{tabular}{|c|c|c|c|c|c|c|}
\hline \multirow[b]{2}{*}{ carbene } & \multicolumn{2}{|c|}{$v_{1}^{b}$} & \multicolumn{2}{|c|}{$v_{2}{ }^{c}$} & \multicolumn{2}{|c|}{$v_{3}{ }^{d}$} \\
\hline & calcd $^{e}$ & $\operatorname{expt}^{f}$ & calcd $^{e}$ & $\operatorname{expt}^{f}$ & calcd $^{e}$ & $\operatorname{expt}^{f}$ \\
\hline \multicolumn{7}{|c|}{ A. Singlets } \\
\hline $\mathrm{CH}_{2}$ & 2781 & 2806 & 1352 & 1352.6 & 2843 & 2865 \\
\hline $\mathrm{CHBr}$ & 643 & 683 & 1107 & & 2811 & \\
\hline $\mathrm{CHCl}$ & 784 & 811.6 & 1183 & 1201 & 2800 & \\
\hline $\mathrm{CHF}$ & 1174 & 1189 & 1403 & 1403.2 & 2678 & 2643 \\
\hline CHI & 548 & & 1023 & & 2806 & \\
\hline $\mathrm{CBr}_{2}$ & 565 & 598 & 188 & 196 & 621 & 641 \\
\hline $\mathrm{CBrCl}$ & 592 & 618 & 253 & 262 & 729 & 744 \\
\hline $\mathrm{CBrF}$ & 635 & 656 & 332 & 325 & 1155 & 1157 \\
\hline CBrI & 491 & & 154 & & 601 & \\
\hline $\mathrm{CCl}_{2}$ & 711 & 748 & 326 & 335.2 & 739 & 730 \\
\hline $\mathrm{CClF}$ & 743 & 759 & 436 & 449 & 1150 & 1156 \\
\hline CClI & 504 & & 211 & & 728 & \\
\hline $\mathrm{CF}_{2}$ & 1118 & 1114.44 & 649 & 666.25 & 1209 & 1225.08 \\
\hline CFI & 552 & 573 & 268 & & 1155 & 1133 \\
\hline $\mathrm{CI}_{2}$ & 457 & & 127 & & 541 & \\
\hline \multicolumn{7}{|c|}{ B. Triplets } \\
\hline $\mathrm{CH}_{2}$ & 3006 & & 1078 & 963.1 & 3218 & 3190 \\
\hline $\mathrm{CHBr}$ & 711 & 725 & 893 & & 3075 & \\
\hline $\mathrm{CHCl}$ & 855 & 850 & 968 & & 3080 & \\
\hline $\mathrm{CHF}$ & $1224^{g}$ & 1232 & $1096^{g}$ & 1047 & 3031 & \\
\hline CHI & 620 & 637 & 823 & & 3068 & \\
\hline $\mathrm{CBr}_{2}$ & 506 & & 178 & & 837 & \\
\hline $\mathrm{CBrCl}$ & 573 & & 236 & & 917 & \\
\hline $\mathrm{CBrF}$ & 647 & & 310 & & 1203 & \\
\hline CBrI & 447 & & 150 & & 798 & \\
\hline $\mathrm{CCl}_{2}$ & 668 & & 295 & & 968 & \\
\hline $\mathrm{CClF}$ & 788 & & 381 & & 1213 & \\
\hline CClI & 496 & & 205 & & 894 & \\
\hline $\mathrm{CF}_{2}$ & 1109 & & 499 & 517 & 1289 & \\
\hline CFI & 545 & & 266 & & 1190 & \\
\hline $\mathrm{CI}_{2}$ & 400 & & 126 & & 753 & \\
\hline
\end{tabular}

${ }^{a}$ In units of $\mathrm{cm}^{-1} \cdot{ }^{b} \mathrm{CX}_{2}$, sym. str.; CXY, low freq. str. ${ }^{c}$ Bend. ${ }^{d} \mathrm{CX}_{2}$, anti-sym. str.; CXY, high freq. str. ${ }^{e}$ Calculated frequencies are at the QCISD/6-311G(d,p) level of theory and have been scaled by the factor 0.954 (see text). ${ }^{f}$ Experimental frequencies from ref 26. ${ }^{g}$ Strongly coupled modes.

TABLE 3: Calculated and Experimental Singlet-Triplet Energy Gaps $\left(\Delta E_{\mathrm{S}-\mathrm{T}}\right)$ in Halocarbenes ${ }^{a, b}$

\begin{tabular}{|c|c|c|c|c|}
\hline carbene & G2 & $\mathrm{QCISD}(\mathrm{T})^{c}$ & experiment & calculated (lit.) \\
\hline $\mathrm{CH}_{2}$ & -27.9 & -40.6 & $-37.65 \pm 0.06^{d, e}$ & $\begin{array}{l}-41.8,^{g}-40.5,^{h} \\
\quad-47.7,,^{i}-36.4^{q}\end{array}$ \\
\hline $\mathrm{CHBr}$ & 35.1 & 20.0 & $10.9 \pm 9.2^{d, f}$ & $17.2,{ }^{j} 27.0^{h}$ \\
\hline $\mathrm{CHCl}$ & 37.7 & 23.7 & $17.6 \pm 10.5^{d, f}$ & $26.1,{ }^{h} 22.6,{ }^{j} 25.1^{k}$ \\
\hline $\mathrm{CHF}$ & 72.7 & 59.8 & $62.3 \pm 1.7^{d, f}$ & $\begin{array}{c}60.7,^{g} 56.0,{ }^{h} 55.2,,^{j} \\
58.2,49.0^{q}\end{array}$ \\
\hline $\mathrm{CHI}$ & 26.5 & 12.5 & -8.4 to $-42^{f}$ & $20.3,^{h} 15.5^{p}$ \\
\hline $\mathrm{CBr}_{2}$ & 81.1 & 63.1 & & $77.4^{q}$ \\
\hline $\mathrm{CBrCl}$ & 88.5 & 72.1 & & \\
\hline $\mathrm{CBrF}$ & 148.1 & 132.2 & & \\
\hline $\mathrm{CBrI}$ & 64.9 & 48.8 & & \\
\hline $\mathrm{CCl}_{2}$ & 96.7 & 82.2 & & $85.8,{ }^{\mathrm{k}} 99.2^{q}$ \\
\hline $\mathrm{CClF}$ & 160.8 & 147.3 & & \\
\hline $\mathrm{CClI}$ & 70.3 & 56.1 & & \\
\hline $\mathrm{CF}_{2}$ & 246.6 & 234.4 & $237.14 \pm 0.02^{d, m}$ & $238.9, g^{g} 226.7,,^{h} 225.9^{q}$ \\
\hline CFI & 122.5 & 109.5 & & \\
\hline $\mathrm{CI}_{2}$ & 52.0 & 36.8 & & $64.9^{q, r}$ \\
\hline
\end{tabular}

${ }^{a}$ In kJ mol ${ }^{-1} .{ }^{b} \Delta E_{\mathrm{S}-\mathrm{T}}=E_{0}($ trip $)-E_{0}(\operatorname{sing})$, and includes ZPE's. ${ }^{c}$ Calculation at the QCISD(T)/6-311+G(3df,2p)//QCISD/6-311G(d,p) level. ${ }^{d}$ Reference 26. ${ }^{e}$ Reference 25. ${ }^{f}$ Reference 27. ${ }^{g}$ Reference 29 [GVB-DCCI]. ${ }^{h}$ Reference 20 [DFT]. ${ }^{i}$ Reference 30 [CASPT2]. ${ }^{j}$ Reference 31 [two configuration CI]. ${ }^{k}$ Reference 32 [GVB-DCCI]. ${ }^{l}$ Reference 33 [CEPA]. ${ }^{m}$ Reference 28. ${ }^{n}$ Reference 22 [MRCI] ${ }^{o}$ Reference $22[\mathrm{CCSD}(\mathrm{T})]^{p}$ Reference 34 [LCGTO-LSD] ${ }^{q}$ Reference 35 [LCGTOLSD] ${ }^{r} 0.9 \mathrm{~kJ} / \mathrm{mol}$ has been added to adjust the value in ref 35 for ZPE.

experiment to within 5.9 and $4.2 \mathrm{~kJ} \mathrm{~mol}^{-1}$, respectively, i.e., to within the target accuracy of the G2 method, whereas the singlet-triplet gap differs from the measured value by a significantly larger amount $\left(10 \mathrm{~kJ} \mathrm{~mol}^{-1}\right)$, due to the presence of noncanceling errors in the latter calculation. This problem in the $\mathrm{G} 2$ calculation of $\Delta E_{\mathrm{S}-\mathrm{T}}$ in $\mathrm{CH}_{2}$ has been noted in a recent review article on structure and energy calculations of carbenes. ${ }^{36}$ The fact that one finds a uniformly positive deviation in values of $\Delta E_{\mathrm{S}-\mathrm{T}}(\mathrm{G} 2)$ from experiment in the halocarbenes offers a cautionary note on the accuracy of the G2 method applied to this type of transition energy calculation.

There is also generally a very good agreement of our values of $\Delta E_{\mathrm{S}-\mathrm{T}}[\mathrm{QCISD}(\mathrm{T})]$ with earlier computed energy gaps, obtained by a variety of other methods (Table 3 ); the greatest differences from our results appear to be some of the transition energies computed with DFT methods, ${ }^{20}$ as well as one of the earlier results for $\mathrm{CH}_{2} \cdot{ }^{31}$ That our values of $\Delta E_{\mathrm{S}-\mathrm{T}}(\mathrm{G} 2)$ lie significantly higher than other computed values provides further evidence that the G2 HLCs degrade the quality of computed singlet-triplet gaps.

There have been at least two alternative explanations of the observed stabilization of the singlet electronic states of carbenes by halogen substituents. ${ }^{3,11}$ In one view, electron-withdrawing substituents occupy orbitals of increased $\mathrm{p}$ character (from Bent' ${ }^{24}$ rule) and thus inductively stabilize the singlet's nonbonding pair of electrons by enhancing the s character of that orbital. Alternatively, it has been proposed that the $\pi$-electron-donating capacity of halogen atoms induce greater stabilization of the singlet by electron donation to the empty $\mathrm{p}$ orbital. Either explanation of the singlet state stabilization leads to the prediction that $\Delta E_{\mathrm{S}-\mathrm{T}}$ should correlate positively with the halogen substituent's electronegativity, since both the $\sigma$-withdrawing and $\pi$-donating capacity of the halogen increase with $\chi$.

To test this prediction, it is again useful to consider variations within a series, CXY, for fixed $\mathrm{X}$ as a function of the electronegativity of the second substituent, Y. In Figure 3, we have plotted $\Delta E_{\mathrm{S}-\mathrm{T}}[\mathrm{QCISD}(\mathrm{T})]$ vs $\chi_{\mathrm{Y}}$, for $\mathrm{X}=\mathrm{H}, \mathrm{I}, \mathrm{Br}, \mathrm{Cl}$, and $\mathrm{F}$. One observes that, with the exception of the computed value for $\mathrm{CH}_{2}$, there is an excellent linear dependence of the energy gap on substituent electronegativity within each series. If the lines for each of the five series were parallel to one another, it would signify that the energy gap is a simple linear function of the sum of the electronegativities. However, one notices a distinct increase in the slope of each line with the electronegativity of the constant substituent. This implies the presence of a synergistic effect, in which the electronegativity of the first substituent affects the influence of the second substituent on the energy gap. The effect is shown more clearly in Figure 3B, where one observes (with $\mathrm{CH}_{2}$ again as the exception) a small but definite positive curvature in the plot of $\Delta E_{\mathrm{S}-\mathrm{T}}$ vs $\chi_{\mathrm{X}}+\chi_{\mathrm{Y}}$.

There has been some controversy over the sign of the singlettriplet energy gap in CHI. The results of some experimental reactivity investigations suggest a ground state singlet, ${ }^{37,38}$ whereas Gilles et al. ${ }^{27}$ note that the results of their PES investigation of the $\mathrm{CHI}^{-}$anion infer that the triplet is energetically more stable, although the estimated error in their experiment is rather large (Table 3). As seen from the table, we have found that $\Delta E_{\mathrm{S}-\mathrm{T}}[\mathrm{CHI}]>0$, consistent with the earlier reactivity studies. To test the effect of using the ECP basis for iodine, we repeated the calculations using the $\mathrm{AE}$ form of the iodine basis sets and obtained very similar results $\left(\Delta E_{\mathrm{S}-\mathrm{T}}[\mathrm{QCISD}-\right.$ $\left.(\mathrm{T})]=11.6 \mathrm{~kJ} \mathrm{~mol}^{-1}\right)$. This does not conclusively prove that the sign of the energy gap is positive. At best, one may argue that $\Delta E_{\mathrm{S}-\mathrm{T}}$ for $\mathrm{CHI}$ is much smaller in magnitude than for 

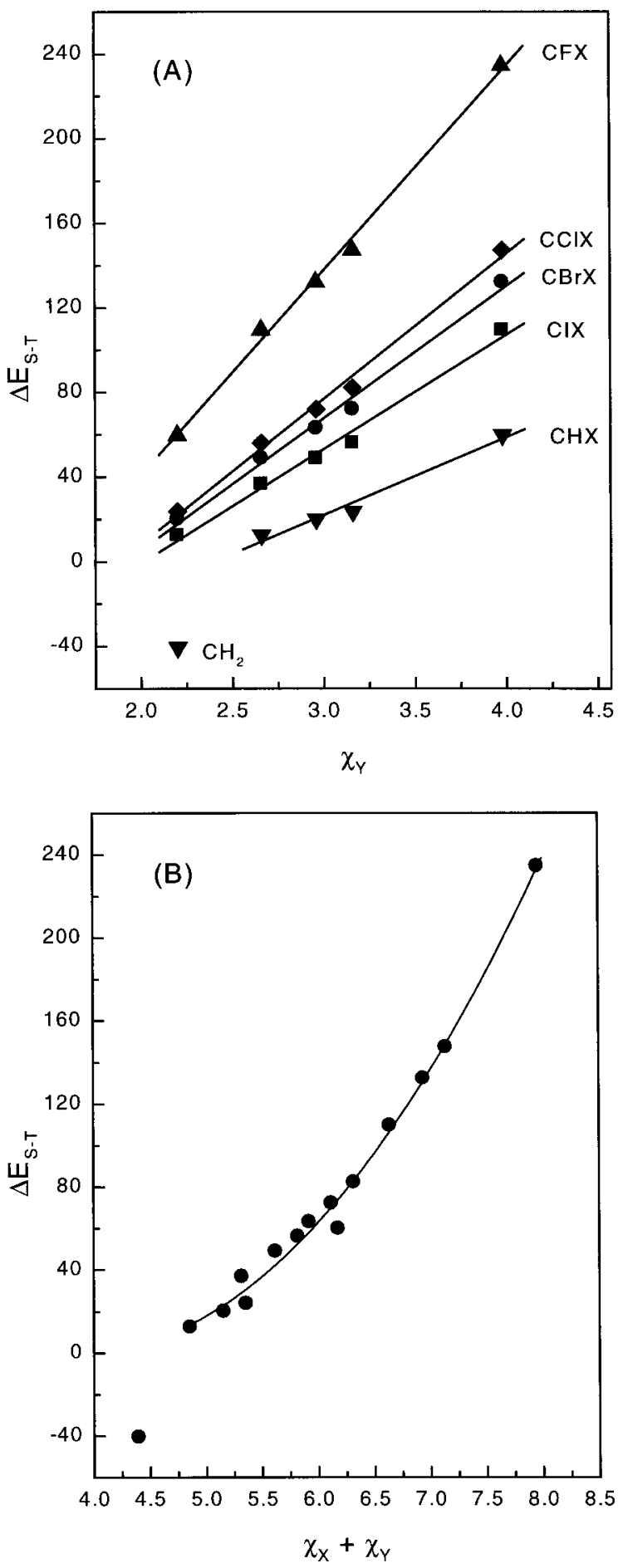

Figure 3. (A) Singlet-triplet energy gaps, $\Delta E_{S-T}$, versus substituent electronegativity, $\chi_{\mathrm{Y}}$, for the series $\mathrm{CXY}(\mathrm{X}=\mathrm{H}, \mathrm{F}, \mathrm{Cl}, \mathrm{Br}, \mathrm{I})$. CHY, down triangles; CFY, up triangles; $\mathrm{CClY}$, diamonds; $\mathrm{CBrY}$, circles; CIY, squares. (B) Singlet-triplet energy gaps, $\Delta E_{\mathrm{S}-\mathrm{T}}$, for CXY versus the sum of substituent electronegativities, $\chi_{\mathrm{X}}+\chi_{\mathrm{Y}}$.

carbenes with more highly electronegative halogen substituents. Thus, CHI in iodine-inhibited flames may well react as an equilibrated mixture of both singlet and triplet states.

C. Enthalpies of Formation. Accurate data on the enthalpies of formation of halocarbenes is essential to modeling the kinetics of haloalkane decomposition at elevated temperatures. Yet, measured enthalpies on almost all of these systems are either lacking completely or reported values are subject to large experimental uncertainties. ${ }^{7-9,39-41}$
It has been demonstrated that the "standard" method of computation of molecular enthalpies of formation from ab initio atomization energies $^{8,42}$ is subject to unacceptably large errors in haloalkanes, particularly those containing fluorine. ${ }^{43} \mathrm{~A}$ standard procedure for minimizing these types of systematic errors is to utilize isodesmic reactions ${ }^{44,45}$ in which the numbers of each type of bond are conserved. For example, to determine the enthalpy of formation of a singlet halocarbene carbene, $\mathrm{CXY}\left({ }^{1} \mathrm{~A}^{\prime}\right)$, one may utilize a reaction of the form: ${ }^{46}$

$$
\mathrm{CH}_{2}\left({ }^{1} \mathrm{~A}_{1}\right)+\mathrm{CH}_{3} \mathrm{X}+\mathrm{CH}_{3} \mathrm{Y} \rightarrow \mathrm{CXY}\left({ }^{1} \mathrm{~A}^{\prime}\right)+2 \mathrm{CH}_{4}
$$

One first computes $\Delta E_{0}\left[=\Delta H^{\circ}(0 \mathrm{~K})\right]$ for this reaction from the $a b$ initio energies and then adds thermal contributions, calculated from computed frequencies and structures using standard formulas, ${ }^{8,42}$ to obtain $\Delta H^{\circ}(298.15 \mathrm{~K})$. One uses this result, together with accurate experimental enthalpies of formation for $\mathrm{CH}_{2},{ }^{47} \mathrm{CH}_{3} \mathrm{X}, \mathrm{CH}_{3} \mathrm{Y}$, and $\mathrm{CH}_{4}{ }^{48}$ to obtain $\Delta_{\mathrm{f}} H^{\circ}(\mathrm{CXY})$. There is no accurate experimental enthalpy of formation of $\mathrm{CH}_{3} \mathrm{~F}$. Therefore, values of $\Delta_{\mathrm{f}} H^{\circ}$ for fluorine-containing carbenes were computed from reactions of the type

$$
2 \mathrm{CH}_{2}\left({ }^{1} \mathrm{~A}_{1}\right)+\mathrm{CH}_{2} \mathrm{~F}_{2}+2 \mathrm{CH}_{3} \mathrm{Y} \rightarrow 2 \mathrm{CFY}\left({ }^{1} \mathrm{~A}^{\prime}\right)+3 \mathrm{CH}_{4}
$$

Enthalpies of formation for halocarbenes, computed from both G2 and QCISD(T) energies, are contained in Table 4, together with available experimental data $^{7-9,39}$ and earlier reported computed values of $\Delta_{\mathrm{f}} H^{\circ} .{ }^{27,39,49-52}$

We note that the computed values of $\Delta_{\mathrm{f}} H^{\circ}$ for the five chlorinated carbenes were determined using eq 1 with $\mathrm{CH}_{3} \mathrm{Cl}$ as the reference halomethane. Since there is also an accurate experimental enthalpy of formation for $\mathrm{CH}_{2} \mathrm{Cl}_{2},{ }^{48}$ we also computed $\Delta_{\mathrm{f}} H^{\circ}$ [QCISD(T)] for the chlorocarbenes from isodesmic reactions of the form in eq 2 [not shown]; the results were very close for the two methods of calculation. ${ }^{53}$ Similarly, there exist accurate experimental values of $\Delta_{\mathrm{f}} H^{\circ}$ for $\mathrm{CHF}_{3}$ and $\mathrm{CF}_{4}{ }^{54}$ (although not for $\mathrm{CH}_{3} \mathrm{~F}$ ). Computed $\mathrm{G} 2$ enthalpies of formation of $\mathrm{CF}_{2}$ from isodesmic reactions involving these species yielded results very close to the value in Table 4,55 obtained with $\mathrm{CH}_{2} \mathrm{~F}_{2}$ as the reference compound.

A comparison of the values of $\Delta_{\mathrm{f}} H^{\circ}[\mathrm{G} 2]$ and $\Delta_{\mathrm{f}} H^{\circ}$ [QCISD(T)] reveals that enthalpies of formation calculated by the two methods agree to within $3 \mathrm{~kJ} \mathrm{~mol}^{-1}$ for all of the halocarbenes, with the sole exception of $\mathrm{CHBr}$, for which the deviation is approximately $9 \mathrm{~kJ} \mathrm{~mol}^{-1}$. The overall good agreement indicates that the improved geometry and frequency calculations in the latter method do not have a significant impact on the computed energies and that either the additivity approximations inherent in the $\mathrm{G} 2$ protocol are accurate or that errors are similar for the various species involved in the isodesmic reactions. Recalling that G2 energy calculations on bromine- and iodine-containing species utilized AE basis sets, whereas the QCISD(T) energies were computed with the ECP bases, one may also conclude from the generally close agreement that relativistic effects (incorporated into the latter calculations only) are either relatively small or cancel because of the use of isodesmic reactions. As noted, the deviation between the two computed enthalpies of formation of $\mathrm{CHBr}$ is much larger than for all other halocarbenes. The authors offer no explanation for this result, since there is much closer agreement for the four other brominated carbenes.

One observes from the fourth column of Table 4 that, as noted above, there are limited experimental data on enthalpies of formation of halocarbenes and, in most cases, the reported accuracy is quite low. One observes from the table that there 
TABLE 4: Calculated and Experimental Enthalpies of Formation $\left[\Delta_{\mathrm{f}} H^{\circ}(298.15)\right]$ of Halocarbenes ${ }^{a, b}$

\begin{tabular}{|c|c|c|c|c|}
\hline carbene & $\mathrm{G} 2^{c}$ & $\mathrm{QCISD}(\mathrm{T})^{c, d}$ & experiment & calculated (lit.) \\
\hline $\mathrm{CHBr}$ & 371.0 & 379.8 & $373 \pm 18^{e}$ & \\
\hline $\mathrm{CHCl}$ & 318.2 & 319.7 & $317 \pm 18,{ }^{e} 335 \pm 42, f 308.3 \pm 30,{ }^{g} 336.4 \pm 11.7,{ }^{h} 297^{r}$ & $317.1,{ }^{i} 321.3,{ }^{j} 315.5,{ }^{k} 318.0^{l}$ \\
\hline $\mathrm{CHF}$ & 145.4 & 146.1 & $157 \pm 18,{ }^{e} 125.5 \pm 29,{ }^{f} 105.3 \pm 25,^{g} 143 \pm 12.6,{ }^{h} 109 \pm 12^{r}$ & $141.8,^{m} 130.1,^{k} 135.1^{l}$ \\
\hline $\mathrm{CHI}$ & 426.6 & 425.2 & $428 \pm 21^{e}$ & \\
\hline $\mathrm{CBr}_{2}$ & 336.0 & 338.8 & $336.6 \pm 50^{g}$ & \\
\hline $\mathrm{CBrCl}$ & 281.7 & 284.7 & & \\
\hline $\mathrm{CBrF}$ & 86.5 & 89.1 & & \\
\hline $\mathrm{CBrI}$ & 394.8 & 395.4 & & \\
\hline $\mathrm{CCl}_{2}$ & 227.3 & 230.1 & $238.5 \pm 21,{ }^{f} 226.2 \pm 20, g^{g} 230.1 \pm 8.4,^{h} 163,{ }^{r} 218.0 \pm 14^{s}$ & $228.0,,^{n} 223.8^{k}{ }^{k} 224.7,{ }^{l} 218.5^{\circ}$ \\
\hline $\mathrm{CClF}$ & 27.8 & 29.4 & $25.9 \pm 30,{ }^{g} 31.0 \pm 13.4,{ }^{h}-20 \pm 29^{r}$ & $21.3,{ }^{k} 28.0,{ }^{l} 24.8^{o}$ \\
\hline $\mathrm{CClI}$ & 342.2 & 342.8 & & \\
\hline $\mathrm{CF}_{2}$ & -196.2 & -196.2 & $-182.0 \pm 6.3,{ }^{f}-180.0 \pm 10,^{g}-205 \pm 12,^{r}-164.8 \pm 14^{s}$ & $-194.5,{ }^{p}-213.8,{ }^{i}-206.3,{ }^{k}-196.6,{ }^{l}-198.9,{ }^{o}-192.6^{q}$ \\
\hline $\mathrm{CFI}$ & 154.4 & 153.6 & & \\
\hline $\mathrm{CI}_{2}$ & 450.3 & 450.1 & $468.4 \pm 60^{g}$ & \\
\hline
\end{tabular}

${ }^{a}$ Values are for the ground state (singlet) halocarbenes. ${ }^{b} \mathrm{In} \mathrm{kJ} \mathrm{mol}{ }^{-1} \cdot{ }^{c}$ Enthalpies computed using isodesmic reactions (see text). ${ }^{d} \mathrm{Calculation}$ at the QCISD(T)/6-311+G(3df,2p)//QCISD/6-311G(d,p) level. ${ }^{e}$ Reference 39. ${ }^{f}$ Reference 8. ${ }^{g}$ Reference $7 .{ }^{h}$ Reference 40(measured, rather than recommended, values). ${ }^{i}$ Reference 49 [MP4SDTQ/6-311++G(2df,p) using isogyric reaction]. ${ }^{j}$ Reference 50 [QCISD(T)/6-311++G(3df,3dp)// MP2/6-311++G(d,p) atomization energies]. ${ }^{k}$ Reference 40 [G2 atomization energies]. ${ }^{l}$ Reference 40 [G2 using isogyric reactions]. ${ }^{m}$ Reference 49 [MP4SDTQ/6-311++G(3df,3pd) using isogyric reaction]. ${ }^{n}$ Reference 50 [QCISD(T)/6-311G(2df,p)//QCISD/6-311G(d,p) atomization energies]. ${ }^{o}$ Reference 51 [CBS-Q atomization energies]. ${ }^{p}$ Reference 52 [CCSD(T) - extrapolation to CBS limit]. Thermal contribution of $0.5 \mathrm{~kJ}$ mol ${ }^{-1}$ was added to $\Delta_{\mathrm{f}} H^{\circ}(0 \mathrm{~K})$ given in reference. ${ }^{q}$ Reference $21\left[\mathrm{CCSD}(\mathrm{T})\right.$, basis set extrapolation, from successive BDEs] ${ }^{r}$ Reference $9{ }^{s}$ Reference 41.

are no experimental determinations on 4 of the 14 halocarbenes and only single measured values (with large experimental uncertainties) on 4 other species. Further, even for the carbenes with three or four measurements, there are very wide discrepancies between the results of different groups using varying experimental methods. For example, the four reported values of $\Delta_{\mathrm{f}} H^{\circ}$ [expt] for CHF vary over a range of $40 \mathrm{~kJ} \mathrm{~mol}^{-1}$, which is much larger than the estimated uncertainties in at least two of the experimental enthalpies. In all cases, our computed enthalpies of formation fall either within the range of different measurements or, for $\mathrm{CBr}_{2}$ and $\mathrm{CI}_{2}$, well inside the quoted experimental uncertainty limits. However, in view of the very low accuracy of some of the experiments on the halocarbenes, this degree of agreement cannot be used to "calibrate" the quality of the calculated values. It is of interest to note that our computed enthalpies of formation for all four monohalocarbenes are rather close (within approximately $10 \mathrm{~kJ} \mathrm{~mol}^{-1}$ ) to recent experimental values (derived from gas-phase acidities) reported by Born et al. ${ }^{39}$

Contained in the final column of Table 4 are earlier calculated values of $\Delta_{\mathrm{f}} H^{\circ}$ for various chloro- and fluorocarbenes, computed by a variety of theoretical methods; the authors are aware of no earlier results for species containing bromine and/or iodine. For two of the five species, where earlier calculations have been performed, $\mathrm{CHCl}$ and $\mathrm{CClF}$, the total range of values, including ours, is $6-8 \mathrm{~kJ} \mathrm{~mol}^{-1}$. The ranges of computed enthalpies for $\mathrm{CCl}_{2}, \mathrm{CHF}$, and $\mathrm{CF}_{2}$ are significantly higher $(12,16$, and $19 \mathrm{~kJ}$ $\mathrm{mol}^{-1}$, respectively). However, one notes that, not unexpectedly, computed values of $\Delta_{\mathrm{f}} H^{\circ}$ using G2 or CBS-Q atomization energies $^{39,51}$ are lower than other values. We have shown in earlier work on fluoro- and chloromethanes ${ }^{42,43,54}$ that enthalpies of formation computed from atomization energies using these methods lead to unacceptably large systematic errors which can be removed by utilizing isodesmic reactions or (closely related) bond additivity corrections. The other "outlier" among the computed enthalpies is the value for $\mathrm{CF}_{2}$ using an isogyric (spin conserved), but not isodesmic (bond types conserved), reaction. ${ }^{49}$ Without these values, the ranges of computed enthalpies of $\mathrm{CCl}_{2}$, $\mathrm{CHF}$, and $\mathrm{CF}_{2}$ are reduced to 6,11 , and $6 \mathrm{~kJ} \mathrm{~mol}^{-1}$, respectively.

As noted in the Introduction, modeling the role of halocarbenes in the decomposition of haloalkanes under combustion conditions requires accurate enthalpies of formation which are not presently available for any of these species. The authors suggest that $\Delta_{\mathrm{f}} H^{\circ}[\mathrm{QCISD}(\mathrm{T})]$ values can serve as estimates of heats of formation of the halocarbenes. On the basis of our earlier studies on the application of these methods to determine heats of formation in halomethanes and halomethylidynes, ${ }^{10,42,43,54}$ we would suggest that the enthalpies computed here are probably accurate to approximately $\pm 10 \mathrm{~kJ} \mathrm{~mol}^{-1}$ and should be useful until such time that more accurate thermochemical experiments on these species become feasible.

Acknowledgment. We thank the Robert A. Welch Foundation (Grants B-657 and B-1174) and the UNT Faculty Research Fund for support of this project and the referees for pointing out additional literature.

Supporting Information Available: Table 1S [contains ab initio G2 and QCISD(T) energies of halocarbenes (singlet and triplet states) and of reference compounds, plus scaled QCISD frequencies of the reference compounds.] This material is available free of charge via the Internet at http://pubs.acs.org.

\section{References and Notes}

(1) (a) Kirmse, W. Carbene Chemistry; Academic: New York, 1972. (b) Carbenes; Moss, R. A., Jones, M., Eds.; Wiley: New York, 1981; Vol. 2. (c) Reactive Intermediates; Jones, M., Moss, R. A., Eds.; Wiley: New York, 1981. (d) Kinetics and Spectroscopy of Carbenes and Biradicals; Platz, M. S., Ed.; Plenum: New York, 1990 and references therein.

(2) Bettinger, H. F.; Schleyer, P. v. R.; Schreiner, P. R.; Schaefer, H. F., III In Modern Electronic Structure Theory and Applications in Organic Chemistry; Davidson, E. R., Ed.; World Scientific: New Jersey, 1997; Chapter 3 and references contained therein.

(3) Liebman, J. F.; Simons, J. In Molecular Structure and Energetics; Liebman, J. F., Greenberg, A., Eds.; VCH Publishers: New York, 1986; Vol. 1, Chapter 3 and references therein.

(4) Schuster, G. B. Adv. Phys. Org. Chem. 1986, 22, 311 and references therein.

(5) Bowman, C. T.; Hanson, R. K.; Davidson, D. F.; Gardiner, W. C., Jr.; Lissianski, V.; Smith, G. P.; Golden, D. M.; Frenklach, M.; Goldenberg, M. GRI-Mech 2.11 (http://www.me.berkeley.edu/gri_mech/).

(6) Halon Replacements; Miziolek, A. W., Tsang, W., Eds.; ACS Symp. Ser. 611; American Chemical Society: Washington, DC, 1995.

(7) Thermodynamic Properties of Individual Substances; Gurvich, L., Veyts, I. V., Alcock, C. B., Eds.; Hemisphere: New York, 1992; Vol. 2.

(8) Chase, M. W., Jr.; Davies, C. A.; Downey, J. R., Jr.; Frurip, D. J.; McDonald, R. A.; Syverud, A. N. JANAF Thermochemical Tables, 3rd ed. J. Phys. Chem. Ref. Data 1985, 14 (Suppl. 1).

(9) Lias, S. G.; Bartmess, J. E.; Liebman, J. F.; Holmes, J. L.; Levin, R. D.; Mallard, W. G. Gas-Phase Ion and Neutral Thermochemistry. J. Phys. Chem. Ref. Data 1988, 17 (Suppl. 1). 

2069.

(10) Marshall, P.; Misra, A.; Schwartz, M. J. Chem. Phys. 1999, 110,

(11) Irikura, K. K.; Goddard, W. A., III; Beauchamp, J. L. J. Am. Chem. Soc. 1992, 114, 48 .

(12) Frisch, M. J.; Trucks, G. W.; Schlegel, H. B.; Gill, P. M. W. Johnson, B. G.; Robb, M. A.; Cheeseman, J. R.; Keith, T. A.; Petersson, G. A.; Montgomery, J. A.; Raghavachari, K.; Al-Laham, M. A.; Zakrzewski, V. G.; Ortiz, J. V.; Foresman, J. B.; Cioslowski, J.; Stefanov, B. B.; Nanayakkara, A.; Challacombe, M.; Peng, C. Y.; Ayala, P. Y.; Chen, W.; Wong, M. W.; Andres, J. L.; Replogle, E. S.; Gomperts, R.; Martin, R. L.; Fox, D. J.; Binkley, J. S.; Defrees, D. J.; Baker, J.; Stewart, J. J. P.; HeadGordon, M.; Gonzalez, C.; Pople, J. A. Gaussian 94, revision E.1; Gaussian: Pittsburgh, PA, 1995.

(13) The reference halomethanes, used in the computation of enthalpies of formation utilizing isodesmic reactions, are $\mathrm{CH}_{2} \mathrm{~F}_{2}, \mathrm{CH}_{3} \mathrm{Cl}, \mathrm{CH}_{2} \mathrm{Cl}_{2}, \mathrm{CH}_{3}$ $\mathrm{Br}$, and $\mathrm{CH}_{3} \mathrm{I}$

(14) Curtiss, L. A.; Raghavachari, K.; Trucks, G. W.; Pople, J. A. J. Chem. Phys. 1991, 94, 7221.

(15) McGrath, M. P.; Radom, L. J. Chem. Phys. 1991, 94, 511.

(16) Glukhovtsev, M. N.; Pross, A.; McGrath, M. P.; Radom, L. J. Chem. Phys. 1995, 103, 1878.

(17) Petek, H.; Nesbitt, D. J.; Darwin, D. C.; Ogilby, P. R.; Moore, C. B.; Ramsay, D. A. J. Chem. Phys. 1989, 91, 6566

(18) Marr, A. J.; North, S. W.; Sears, T. J.; Ruslen, L.; Field, R. W. J. Mol. Spectrosc. 1998, 188, 68.

(19) Bunker, P. R.; Jensen, P.; Kraemer, W. P.; Beardsworth, R. J. Chem. Phys. 1986, 85, 3724 .

(20) Worthington, S. E.; Cramer, C. J. J. Phys. Org. Chem. 1997, 10 , 755.

(21) Ricca, A. J. Phys. Chem. A 1999, 103, 1876.

(22) Schmidt, T. W.; Backsay, G. B.; Kable, S. H. Chem. Phys. Lett. 1998, 292, 80 .

(23) (a) Pauling, L., The Nature of the Chemical Bond, 3rd ed.; Cornell University Press: Ithaca, NY, 1960; p 93. (b) Allred, A. L. J. Inorg. Nucl. Chem. 1961, 17, 215 .

(24) (a) Bent, H. A. J. Chem. Phys. 1960, 33, 1258. (b) Bent, H. A. Chem. Rev. 1961, 61, 275.

(25) Janson, P. Bunker, P. R. J Chem Phys 1988, 89, 1327.

(26) (a) Jacox, M. E. J. Phys. Chem. Ref. Data 1998, 27, 115. (b) Jacox, M. E. Vibrational and Electronic Energy Levels of Polyatomic Transient Molecules. J. Phys. Chem. Ref. Data 1993, Monograph 3.

(27) Gilles, M. K.; Ervin, K. M.; Ho, J.; Lineberger, W. C. J. Phys. Chem. 1992, 96, 1130.

(28) Zhou, S.; Zhan, M.; Qin, Y.; Lin, S.; Shi, J.; Li, F.; Yao, J. Chem. Phys. Lett. 1985, 121, 395.

(29) Shin, S. K.; Goddard, W. A., III; Beauchamp, J. L. J. Chem. Phys. 1990, 93, 4986

(30) Schreiner, P. R.; Karney, W. L.; Schleyer, P. v. R.; Borden, W. T.; Hamilton, T. P.; Schaefer, H. F., III J. Org. Chem. 1996, 61, 7030.

(31) Scuseria, G. E.; Duràn, M.; McLagan, R. G. A. R.; Schaefer, H. F., III J. Am. Chem. Soc. 1986, 108, 3248.
(32) Garcia, V. M.; Castell, O.; Reguero, M.; Caballol, R. Mol. Phys 1996, 87,1395

(33) Weis, B.; Rosmus, P.; Yamashita, K.; Morokuma, K. J. Phys. Chem. 1990, 92,6635 .

(34) Russo, N.; Sicilia, E.; Toscano, M. Chem. Phys. Lett. 1993, 213, 245.

(35) Russo, N.; Sicilia, E.; Toscano, M. J. Chem. Phys. 1992, 97, 5031

(36) Bettinger, H. F.; Schleyer, P. v. R.; Schreiner, P. R.; Schaefer, H. F., III In Modern Electronic Structure Theory and Applications in Organic Chemistry; Davidson, E. R., Ed.; World Scientific: New Jersey, 1997; Chapter 3; p 99.

(37) Yang, N. C.; Marolewski, T. A. J. Am. Chem. Soc. 1968, 90, 5644

(38) Kikuchi, M.; Church, L. B. Radiochim. Acta 1973, 20, 81.

(39) Born, M.; Ingemann, S.; Nibberlung, N. M. M. J. Am. Chem. Soc. 1994, 116, 7210.

(40) Poutsma, J. C.; Paulino, J. A.; Squires, R. R. J. Phys. Chem. A 1997, 101, 5326 .

(41) Paulino, J. A.; Squires, R. R. J. Am. Chem. Soc. 1991, 113, 5573.

(42) Berry, R. J.; Schwartz, M.; Marshall, P. In Computational Thermochemistry; Irikura, K. K., Frurip, D. J., Eds.; ACS Symp. Ser. 677; American Chemical Society, Washington, DC, 1991; Chapter 18 and references therein.

(43) Berry, R. J.; Burgess, D. R. F., Jr.; Nyden, M. R.; Zachariah, M. R.; Melius, C. F.; Schwartz, M. J. Phys. Chem. 1996, 100, 7405 and references therein.

(44) Hehre, W. J.; Ditchfield, R.; Radom, L.; Pople, J. A. J. Am. Chem. Soc. 1970, 92, 4796 .

(45) Hehre, W. J.; Radom, L.; Schleyer, P. v. R.; Pople, J. A. Ab Initio Molecular Orbital Theory; Wiley: New York, 1986.

(46) Equation 1 will of course reduce to $\mathrm{CH}_{2}\left({ }^{1} \mathrm{~A}_{1}\right)+\mathrm{CH}_{3} \mathrm{X} \rightarrow \mathrm{CHX}$ $\left({ }^{1} \mathrm{~A}^{\prime}\right)+\mathrm{CH}_{4}$ when one of the carbene's substituents is hydrogen.

(47) The enthalpy of formation of $\mathrm{CH}_{2}\left({ }^{1} \mathrm{~A}_{1}\right)$ used in the isodesmic calculations is $\Delta_{\mathrm{f}} H^{\circ}(298.15 \mathrm{~K})=426.8 \mathrm{~kJ} \mathrm{~mol}^{-1}$, derived from the following source: Doltsinis, N. L.; Knowles, P. J. J. Chem. Soc., Faraday Trans. 1997, 93, 2025

(48) The experimental enthalpies of formation of $\mathrm{CH}_{4}$ and the reference halomethanes are contained in our earlier study. ${ }^{10}$

(49) Rodriquez, C. F.; Hopkinson, A. C. J. Phys. Chem. 1993, 97, 849

(50) Rodriquez, C. F.; Bohme, D. K.; Hopkinson, A. C. J. Phys. Chem. 1996, 100, 2942.

(51) Cheong, B.-S.; Cho, H. G. J. Phys. Chem. A 1997, 101, 7901.

(52) Dixon, D. A.; Feller, D. J. Phys. Chem. A 1998, 102, 8209.

(53) Values of $\Delta_{\mathrm{f}} H^{\circ}[\mathrm{QCISD}(\mathrm{T})]$ for the monochloromethanes obtained using $\mathrm{CH}_{2} \mathrm{Cl}_{2}$ as a reference were uniformly $0.6 \mathrm{~kJ} \mathrm{~mol}^{-1}$ lower than the values in Table 4. Likewise, the computed enthalpy of formation of $\mathrm{CCl}_{2}$ was $1.2 \mathrm{~kJ} \mathrm{~mol}^{-1}$ lower. These small differences reflect minor inconsistencies in the experimental enthalpies of formation of $\mathrm{CH}_{3} \mathrm{Cl}$ and $\mathrm{CH}_{2} \mathrm{Cl}_{2}$.

(54) Berry, R. J.; Burgess, D. R. F., Jr.; Nyden, M. R.; Zachariah, M R.; Schwartz, M. J. Phys. Chem. 1995, 99, 17145 and references therein.

(55) $\mathrm{G} 2$ enthalpies of formation for $\mathrm{CF}_{2}$ calculated using either $\mathrm{CHF}_{3}$ or $\mathrm{CF}_{4}$ as the reference species are -195.7 or $-194.4 \mathrm{~kJ} \mathrm{~mol}^{-1}$, respectively. 